\title{
Enterprise Networking Modeling Based on Knowledge Management for Family Enterprises
}

\author{
Víctor Hugo Medina García, Angie Elizabeth Sánchez, and Alexis Ortiz Morales
}

\begin{abstract}
This paper present the methodology for modeling and simulation of an enterprise networking that is based on knowledge management and collaborative development of social technologies for SMEs in the major economic family settings in Bogota D.C. (from now FamiSMEs).

The need for performance of the model is exposed, some background business networks and the proposed methodology through which seeks to achieve, which combines both knowledge management, as the simulation model so that it becomes a tool evaluation for companies and government entities that mesure possible impact on these organizations.
\end{abstract}

Index Terms-Knowledge management, family SMEs, enterprise networking, social technology, modeling and simulation.

\section{INTRODUCTION}

On the one hand, social technologies are a way to design, develop, implement and manage aimed at solving social problems and / or environmental, generating economic dynamics of social inclusion and sustainable development, which allows the resolution of problems such as poverty, exclusion technologies and underdevelopment. In this regard, we wish to model and simulate an enterprise networking that is based on the knowledge management's own held family business communities as well as the development of social technologies (soft technologies) for increasing competitiveness in Bogota family enterprises.

Moreover, economic conditions and processes of migration that has seen the city have contributed to the proliferation of informality as support mechanism, where families formed small units of work to support the family. As a result, these production units originate in high social vulnerability, isolation, low productivity and competitiveness, coupled with a general disinterest in the use of technology or innovation in products, processes or services.

Under the methodology described in this article to the design of a technological network FamiSMEs of Bogota D.C., active and dynamic relations between the agents evaluate the enterprise networking and the capacity for innovation and knowledge generation will examine the FamiSMEs to generate solutions to economic, efficient and sustainable

Manuscript received July 31, 2015; revised December 9, 2015.

Víctor Hugo Medina Garcia and Alexis Ortiz Morales are with the District University Francisco José de Caldas, Bogotá, Colombia (tel.: 3239300 ext. 1711, 1010, 1012; e-mail: vmedina@udistrital.edu.co, alexis_adamy@hotmail.com).

Angie Elizabeth Sánchez is with Colciencias (Departamento Administrativo de Ciencia, Tecnología e Innovación), Bogotá, Colombia (e-mail: anesanchezs@correos.udistrital.edu.co). technological alternatives. From the model is expected to simulate scenarios in which the impact of public policies and the design of instruments aimed at improving the capabilities of innovation, technological development, increased productivity and competitiveness of FamiSMEs be evaluated.

\section{CONCEPTUALIZATION}

\section{A. Why in the Family SMEs?}

Family enterprises have a great importance for the economy of the countries. In the European Union around $60 \%$ of companies are families and employ 100 million people. In the United States, generate between $40 \%$ and $60 \%$ of GDP and $50 \%$ of jobs. In Britain, $76 \%$ of large companies are family. In Colombia, representing $70 \%$ of companies and Bogota D.C. it has a representation $65 \%$. In Colombia family enterprises are a major source of job creation as the National Federation of Trade FENALCO [1].

They characterized because its members are members of the founder and owner family, however many of them are linked not by corporate commitment, but because they cannot get jobs in other companies with the highest degree of formality, therefore are in need of participate as human capital and in some cases also involved people close to the family unit, which does not generate a commitment to sustainability of the company. That is why the "key element to be analyzed in the family enterprise is the relationship between the family and business systems, which support the sustainability of the family enterprise or the cause of its demise" [2].

According to the consultancy Global Management, $68 \%$ of companies existing in our country are relatives (of formalized) and it is estimated that over $30 \%$ of family enterprise survive into the second generation, and about $13 \%$ goes to the third (Money, 2013). The family enterprise generates $60 \%$ of GDP in Colombia [3].

\section{B. Why a Network of Enterprise Knowledge Management?}

The networking of business knowledge management is a strategy that will allow the dissemination of information and the combination of knowledge, based on mutual trust, as it promotes partnerships between companies, support institutions and other related organizations.

A networking of knowledge management is posed because its operation has the advantage of flexibility, adaptation to changes and achieving goals that could not be achieved in isolation. Understand the workings of this network to manage knowledge will be the determining factor in the success or failure of this configuration [4]. 


\section{Why a Simulation Model?}

It is through simulation that complex organizational systems can predict, compare and optimize the results of a process without the cost and risks involved. Through simulation observations are generated in key variables, through a statistical analysis of the resulting data, given the understanding of the system without exposing or alter the actual operation. Its importance lies in its usefulness to raise the strategy to be followed from the experimental point of view, to understand on operation and generate predictive rules over time, where a representative role plays using systems [5].

System dynamics studies the characteristics of feedback information in industrial activity to show how organizational structure, amplification (policy) and delays (in decisions and actions) interact and influence the success of the company [6] in this sense, this method combines the analysis and synthesis by providing a language for expressing reactions that occur within a system and we could give explanations and predictions of their behavior [7].

\section{EVOLUTION OF ENTERPRISES NETWORKING}

Enterprise networks have been designed as a combination of various strategies for the dissemination of information and knowledge, based on mutual trust, it seeks to establish partnerships between companies and between the different support institutions or other organizations linked to the network. Around the world there are many enterprise networks in the US enterprise networks are identified with spontaneous concentrations of undertakings and other geographically localized agents that interact naturally and on their own initiative, generating $31.8 \%$ of employment in USA and technology sectors advanced.

Among other cases of networks we have Mexico, Chile, Argentina and Brazil. In Mexico since 2004 under the "Mexico undertake" the Ministry of Economy provides a $70 \%$ subsidy programs consulting, training, weekly monitoring the business, financial runs and business plans [8].

In Chile also, under the Technical Assistance Fund (FAT) is subsidized up to $50 \%$ the hiring of specialized consultants of other companies in various fields of business management, and in the type FAT Clean Production cofinancing up allowed $70 \%$ for companies with few resources can be strengthened.

In Argentina, the "SME Expert" program, hiring professionals specifically evaluated by the Secretariat of the industrial sector must demonstrate academic training and experience of at least ten years in senior positions of leading companies, is financed for SMEs and entrepreneurs to take a leap of quality, optimizing their production processes and technology intensive [8].

Finally, in Brazil FINEP (Financier of Studies and Projects), the IPT (Institute for Technological Research) and Sibratec (Brazilian Technology System) provides a way to provide their knowledge subsidized by $90 \%$ of vulnerable entrepreneurs with the aim of strengthen companies that do not have sufficient resources to undertake such roads by themselves [8].

In Colombia, the government began to promote entrepreneurship through education and training for technical work with the creation of the National Apprenticeship Service SENA in 1959, the late twentieth century the first business development centers were created and the-century building laws SMEs and entrepreneurship units were issued; currently it is promoting entrepreneurship through education, public entities and Entrepreneurship Fund, universities and NGOs, as well as other mixed character [9].

With entrepreneurship units SENA has fostered a biased network oriented exclusively towards creating business plans, with interest in obtaining resources to undertake seed capital fund. This approach leads to two results: First if the project submitted is approved, the unit trains and advises the creation and consolidation of the projected enterprise, then interventory are performed to verify compliance indicators, but does not perform an accompaniment to ensure success of the business idea, do not real innovation processes and use of technology are performed so after a while does not make them sustainable and profitable, so few companies undertaking supported by the fund remain on the market or are successful [10].

If the indicators and expected results are not met, there will be a refund of allocated resources [11]. On the other hand, if the business plan is rejected, then the business idea usually stay only in that, in a business idea around.

Another mechanism for seeking a professional network for those without resources, as FamiSMEs small established in the city, is to use enterprise networks that are managing Chamber of Commerce, it is clear that this medium is possible only if the business is legalized, and is known as more than half of businesses are informal, which is why few companies can access these networks.

Now, by various universities and various organizations they have given many regional business networks, among these we act family enterprises, Crown Foundation, entrepreneurial office of the National University in Bogotá, Center for Entrepreneurship Development of ICESI University, Consulting plains Business University, St. Thomas University business office, among many others.

The first organizations with the primary objective of providing financial support to small businesses that meet the requirements, the latter mainly aimed at providing business support students in their respective institutions consultations, but are not intended, nor are small family based on the use of technology.

\section{NeTWORK PARTNERSHIP PROJECT CONSTRUCTION}

For the construction of a network partnership project is decisive in its success or failure the following factors [12].

- Your capacity to negotiate, to talk, to think collectively and clear leadership.

- The existence of a basis of trust, so companies must partner with the capacity to work in groups and to maintain a permanent motivation to results.

- Economic performance and cohesion among entrepreneurs shared vision and trust. This represents a highly complex process by which different interactions 
resulting.

It is important to consider that the operation of the networks has the advantage of flexibility (rapid adaptation to external stimuli) but also have a problem, that is coordination. Effectiveness is one of the central aspects of the theory of systems in organizations understood as the extent to which increasing all forms of energy recovery organization, determined by a combination of its efficiency as a system and its success in obtaining the necessary inputs [12].

\section{FAMILY SMES TECHNOLOGIES IN BOGOTA}

The use of technology in the company currently represents a central role because it determines the behavior of the actors, consumption, production costs, access to goods and services and generate additional social and environmental problems. Seen in this way, the solution of social problems such as povertythe exclusion and underdevelopment they can not be analyzed without considering the technological dimension [13].

There is a clear relationship between the competitiveness of Famipymes and lack of technology that dramatically determines their ability to develop links with other activities and strategies [14]. Large part of their products and processes have serious quality problems associated with obsolete technology, with an absence of maintenance processes and innovation and artisanal production with high costs, which are clearly products of knowledge management an absence.

Among the main reasons why Family SMEs must manage their tacit knowledge and technology development, we have:

- Knowledge in Family SMEs tends to be tacit, informal and unrecorded.

- The know-how in Family SMEs is not valued as it should.

- The shortage of know-how can be difficult to detect in Family SMEs.

- They have short-term solutions to the problems caused by lack of knowledge and have a temporary operation.

- The Know-How a Family SMEs can easily be lost or fragmented when the owner sells the business or retires.

Therefore, government entities and family enterprises need to properly manage their knowledge and resources to meet the technological needs of SMEs and increase their participation in the market with the design of new products and / or services, the improvement of production processes and the generation of added value to raise its competitiveness skills that can be developed internally or acquired from third parties [15].

Of course, to develop capacities internally it requires a deep understanding of the organization and its technology needs, for the establishment of a technology could mean for a successful FamiSMEs increase its capacity or its disappearance. Of there the relevance of a model to simulate how to manage knowledge that ensure meet the technological needs and require an increased competitiveness, social inclusion and a decrease of the economic difficulties facing these organizations.

\section{Methodology}

The methodology presented for the analysis of social problems through system dynamics used was developed by the research group "expert systems and simulation" (SES) of the University District, which was the guide for this proposal [16], in regard to simulation.

Faced with the evaluation of existing networks for knowledge management, the European Good Practice Guide was used in Knowledge Management, specifically Chapter 3 Implementation in Small and Medium Enterprises (SMEs), which was conducted by the CEN Committee (European Committee for Standardization, designed and approved by a group of representatives of all interested parties [17].

This guide discusses a general scheme which covers the following five phases (Fig. 1):

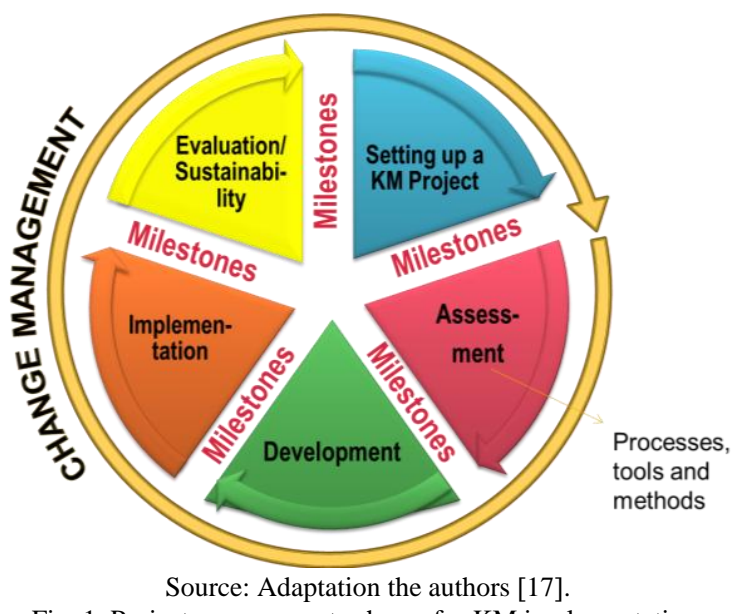

Fig. 1. Project management scheme for KM implementation.

Phase A. Setting up Knowledge Management Project (KM): In this first phase, the vision, mission, strategy and objectives for the KM initiative must be defined and the objectives set. This task is not a one-off exercise, but an iterative process. The defined strategy and aims have to be reviewed in the light of future market requirements, the development of knowledge in the respective areas inside and outside of the organization and the results of the ongoing KM initiative.

Phase B. Assessment: The current state of business conditions, several self-assessment techniques are proposed. Many SMEs may not have the experience and the necessary methods to rate their KM activities.

Phase C. Development: Define the main elements of the solution KM (tools and methods). That is, the main building blocks of the KM solution are identified, planned, designed and prepared for the subsequent implementation process.

Phase D. Implementation: Covers processes KM solution put into practice in the organization and, if appropriate, how to training the end users of the tools and methods.

Phase E. Evaluation/Sustainability: An assessment of the project and results. It is often the ultimate aim of KM to integrate into the work processes of an organization - that is, to become sustainable. But it cannot be expected that this integration will happen overnight and/or by management diktat [17].

This guide provides a methodology in project management to help SMEs (and other organizations, among which are expected to apply to FamiSMEs) to start using knowledge management. It is important to clarify that this proposal, the phases D and E were not worked, because only the modeling and implementation contemplated. 
In Fig. 2, the proposed methodology for building an enterprise networking based on knowledge management for the development of Social Technologies in FamiSMEs model is presented.

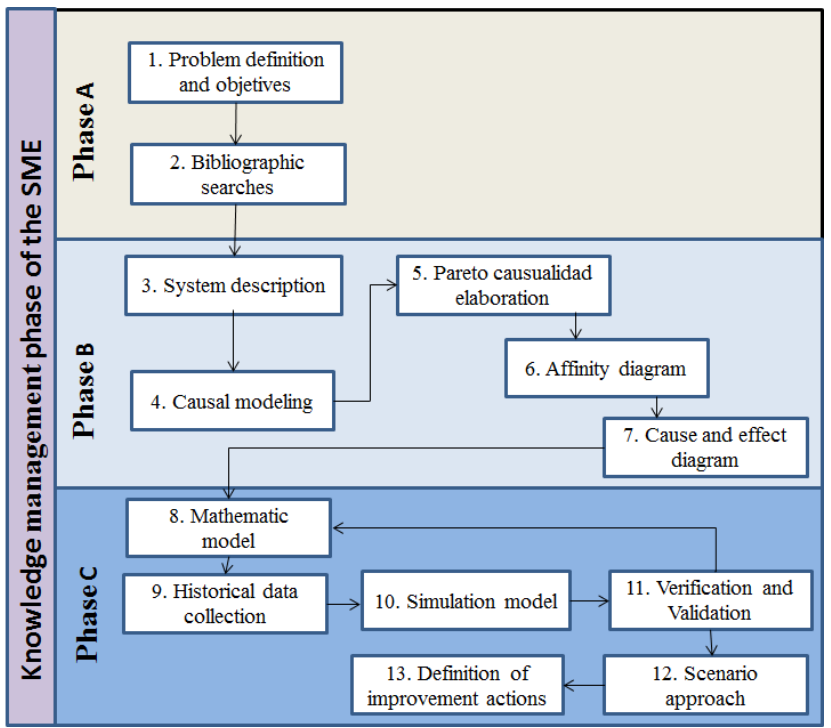

Source: Authors.

Fig. 2. Proposed methodology for enterprise networking based on the KM.

\section{Phase A:}

Problem Definition and Objetives: Defining the problem and objectives is often the hardest step in research process. The manager may know that something is wrong, without knowing the specific causes. Objectives are a specific result that person or system aims to achieve within a time frame and with available resources. Objectives are basic tools that underlie all planning and strategic activities. They serve as the basis for creating policy and evaluating performance.

Bibliographic Searches: Allows to search bibliographic entries of reference works that were used to compile the biographical archives.

\section{Phase B:}

System Description: Is the description that defines the structure, behavior, and more views of a system. It's a formal description and representation of a system, organized in a way that supports reasoning about the structures and behaviors of the system.

Causal Modeling: A causal model is an abstract model that describes the causal mechanisms of a system. The model must express more than correlation because correlation does not imply causation. A causal model is an abstract quantitative representation of real-world dynamics. Hence, a causal model attempts to describe the causal and other relationships, among a set of variables.

Pareto Causualidad Elaboration: The purpose of a Pareto diagram is to separate the significant aspects of a problem from the trivial ones. By graphically separating the aspects of a problem, a team will know where to direct its improvement efforts. Reducing the largest bars identified in the diagram will do more for overall improvement than reducing the smaller ones.

Affinity Diagram: The affinity diagram organizes a large number of ideas into their natural relationships. This method taps a team's creativity and intuition.
Cause and Effect Diagram: Identifying the likely causes of problems. Also known as Cause and Effect Diagrams, Fishbone Diagrams, Ishikawa Diagrams, Herringbone Diagrams, and Fishikawa Diagrams.

This diagram-based technique, which combines Brainstorming with a type of Mind Map, pushes you to consider all possible causes of a problem, rather than just the ones that are most obvious.

\section{Phase C:}

Mathematic Model: A mathematical model is a description of a system using mathematical concepts and language. Mathematical models must take dynamical systems form.

Historical Data Collection: The ability to review a process in retrospect is the function of historical data collection. Done properly, it provides valuable insights that can be used to fine-tune process parameters, justify process improvements, troubleshoot equipment and identify cost savings. Historical data collection can often be accomplished with a single, local HMI (Human Machine Interface) or through a database server residing either locally or remotely at a corporate headquarters.

Simulation Model: Is the process of creating and analyzing a digital prototype of a physical model of a FamiSMEs to predict its performance in the real world. Simulation modeling is used to help designers and engineers understand whether, under what conditions, and in which ways a part could fail and what loads it can withstand.

Verification and Validation: Verification is the process of determining that a model implementation and its associated data accurately represent the developer's conceptual description and specifications [18]. Verification answers the question "Have we built the model right?" whereas validation answers the question "Have we built the right model?" [19]. In other words, the verification phase of VV\&A focuses on comparing the elements of a simulation model of the system with the description of what the requirements and capabilities of the model were to be.

Validation is the process of determining the degree to which a simulation model and its associated data are an accurate representation of the real world from the perspective of the intended uses of the model [18].

Scenario Approach: The 'scenario approach' is an innovative technology that has been introduced to solve optimization problems with an infinite number of constraints, a class of problems which often occurs when dealing with uncertainty. This technology relies on random sampling of constraints, and provides a powerful means for solving a variety of design problems in systems and control organizational.

Definition of Improvement Actions: To facilitate the definition of improvement actions, the organisation (FamiSMEs)) has access to an overview of the areas of improvement highlighted during the self-assessment.

Improvement actions are defined based on the areas of improvement. These improvement actions are documented through the use of a project form with the relevant descriptive fields (e.g. cause, objective, resources, etc.). This form also allows for progress control of the improvement actions during a certain time. 


\section{Methodology Validation Considerations}

For the validation of the methodology, time and evaluation of results in the medium term is required, which is being implemented, why cannot yet present in this paper.

In the methodology presented in this research, the dynamic analysis of systems with knowledge management methodology proposed by the European Guide is combined, and aims to create an assessment instrument of knowledge management network in the introduction incremental innovations in product, service and process for FamiSMEs, that deploy a range of possibilities for development and innovation of social technologies, so that leads organizations to Bogota, increase their competitiveness and reduce socio-economic difficulties that afflict both.

Furthermore, it is possible to deduce that the competitiveness of FamiSMEs increase when the lines of knowledge and methodologies act synergistically in conjunction with contextual factors as the country's trade policies, tax policies, investment security and others, achieving an economic and productive development in the organization.

\section{CONCLUSIONS}

A joint networking allows productivity standards gradually improve quality of life, and generate awareness in the legalization of FamiSMEs and leading to increasing their competitiveness.

Since these units family organizations informal are a structure that lacks many administrative elements that will ensure the competitiveness and the result of the need generated by various socio-economic factors, through the network, it can provide training and professional advice relevant character on the achievement of results. The sensitivity that can be generated with the network is a key factor to the research process forward firmly and successful.

Finally, it is considered that this proposal can be extended to the international realm, generating other interaction with relevant social approach to the requirements of the respective communities.

\section{ACKNOWLEDGMENT}

The authors wish to thank District University Francisco José de Caldas. This work was supported in part by a grant from master in Industrial Engineering.

\section{REFERENCES}

[1] G. Jiménez, The Family Business Their Importance and Validity, Institute of Family Business of Colombia, Medellín, 2009.

[2] M. Rodríguez, J. Rodríguez, and M. Rodríguez., Family Business: Involvement and Achievements of Their Constituents, June 2006.

[3] J. C. Valda, "The family business in Colombia," Large Obtained SMEs, January 6, 2010 .

[4] W. D. González, "Business networks: Experiences and strategies for the development of competitiveness in the regions," Journal MBA EAFIT, pp. 74-82, 2011.
[5] C. Fullana and E. Urquía, Simulation Models: A Multidisciplinary Research Tool, Pontificia University of Comillas, Spain, 2009.

[6] J. Forrester, "System dynamics - Future opportunities," TIMS Series in the Management Sciences, vol. 14, Amsterdam: North Holland, 1980.

[7] J. Aracil and F. Gordillo, System Dynamics, Alianza Editorial, 1997.

[8] S. A. Pedrozo, Programa estadual investe $R \$ 1 \mathrm{mi}$ em empresas da região. March 7, 2010

[9] J. Gámez, “Approach to enterprise models," Management, pp. 153-170, January-June 2009.

[10] S. Herrera, "A look at the factors sustaining some SMEs supported by the Entrepreneurship Fund," LUPA Empresarial, vol. 13, pp. 84-98, July-December 2011.

[11] SENA. (2006). National learning service. [Online]. Available: http://www.fondoemprender.com/BancoMedios/Documentos \%20PD F/separata.pdf

[12] F. M. Serra, "Social networks, systems thinking and system dynamics: Contributions to communicating and estrategar," FISEC — Estrategias, vol. 11 , pp. 149-168, 2008

[13] H. Thomas, "Appropriate technologies to social technologies," Group of Social Studies of Technology and Innovation, 2010.

[14] C. Galve and Gargallo, Working Paper 2004-05. Impact of Information Technologies in Spanish Companies, Spain: FamiSMEs Chair of the University of Zaragoza, 2004.

[15] A. Hidalgo, "The technology strategy in FamiSMEs," Management FamiSMEs, McGraw-Hill, pp. 73-90, 2007.

[16] G. A. Méndez, "System dynamics and social problems," Citizenship and Democracy, District University, 2012.

[17] CEN - Comité Européen de Normalisation, "European guide to good practice in knowledge management," CEN Workshop Agreement, 2004.

[18] DoD Modeling and Simulation (M\&S) Verification, Validation, and Accreditation (VV\&A), DoD Instruction 5000.61, December 9, 2009.

[19] D. A. Cook and J. M. Skinner, "How to perform credible verification, Validation, and accreditation for modeling and simulation," CrossTalk: The Journal of Defense Software Engineering, May 2005.

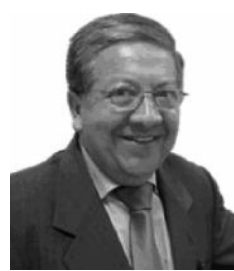

Víctor Hugo Medina García was born in Santa Rosa de Viterbo, Colombia. He received the $\mathrm{PhD}$ degree in computer engineering from the Pontificia of Salamanca University, DEA languages, systems and software engineering and the master in computer science at the Politécnica University of Madrid in Spain, specialist in marketing from the Rosario University and Systems Engineering of the District University "Francisco José de Caldas" of Colombia. He is currently a researcher and senior lecturer at the Faculty of Engineering at the District University "Francisco José de Caldas" in Bogotá, Colombia, where he is extension director of engineering faculty, he was the director of engineering doctorate. He is also a professor in UNIR - International University of the Rioja and he was the coordinator, associate professor and the visiting professor in computer engineering from the Pontificia of Salamanca University campus of Madrid, Spain. His area of work and research is knowledge management and software engineering.

Angie Elizabeth Sánchez is industrial engineering from the District University Francisco José de Caldas, Candidate for the master of industrial engineering at the same University. She is work in Colciencias, Departamento Administrativo de Ciencia, Tecnología e Innovación as professional university in Bogotá.

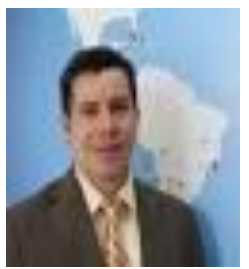

Alexis Adamy Ortiz Ortiz is industrial engineering from the District University Francisco José de Caldas, Doctor Candidate for Pontificia University of Salamanca. $\mathrm{He}$ is currently the director of International Relations Office at District University Francisco José de Caldas in Bogotá. 